\title{
Chemical contents and blue mould susceptibility in Swedish- grown cider apple cultivars
}

\author{
T. Spoor, K. Rumpunen, J. Sehic, A. Ekholm, I. Tahir and H. Nybom \\ Department of Plant Breeding, Swedish University of Agricultural Sciences, Sweden
}

\begin{abstract}
Summary
Craft apple cider is obtained by fermentation of juice from tannin-rich cider apple cultivars. Polyphenols in cider apples are very important; while procyanidins are the only true tannins, other phenolic compounds can act as precursors for cider aroma. Several recent studies have also reported that a high content of polyphenols in apple decreases susceptibility to the common storage rot blue mould caused by Penicillium expansum. Chemical content was determined in fruit of 19 Swedish-grown cider apple cultivars and 5 dessert apple cultivars in 2016. Inoculation with blue mould spores was undertaken in 2016 on 5 cider apple cultivars and 5 dessert apple cultivars, and repeated again in 2017 on 8 of these cultivars. Contrary to expectations, the cider apple cultivars were significantly more susceptible to blue mould in spite of their higher phenolics content. Although apparently unrelated to amount of phenols in the fruit of our study cultivars, heritability of blue mould susceptibility should be further investigated since all of the cider apples had one parent in common: 'James Grieve'.
\end{abstract}

Keywords

DNA, Malus domestica, Penicillium expansum, polyphenols, resistance, SSR, storage rot, tannin

\section{Introduction}

A world-wide increased interest in fruit- and berry-based beverages is apparent in connection with the 'locally produced' and 'health food' consumer trends. Among these are apple cider (hard cider), produced by fermentation of apple juice, usually to $1-8 \%$ alcohol per volume. Apple cider (hard cider) is the fastest growing segment of alcoholic beverages in USA with a 22-fold increase 2007-2015 (Alexander et al., 2016), and is rising also in Europe.

The juice is often pressed from tannin-rich cider apple cultivars in order to impart the characteristic, somewhat bitter taste encountered in high-quality cider (craft cider) (Lea, 1995; Sanoner et al., 1999). Historically, cider production has been especially important in Britain, France and Spain, where a number of traditional cider cultivars are grown. In addition, some cultivars were developed in breeding programs conducted in the 1980s and 1990s by Long Ashton Research Station in England and by INRA at Angers in France. Major aims were resistance to abiotic and biotic stresses, good fruit quality, and high and regular production. In addition, early harvesting (i.e., September) was targeted at Long Ashton to avoid the logistic bottle-necks at cider factories in October when most of the traditional cultivars are harvested.

\section{Significance of this study}

What is already known on this subject?

- Blue mould causes postharvest loss in apple through wound infection. Cider apples are rich in tannins, which may offer protection against blue mould.

What are the new findings?

- In spite of a high polyphenol content, fruit of Swedishgrown cider cultivars was more susceptible to blue mould than fruit from dessert cultivars.

What is the expected impact on horticulture?

- High blue mould susceptibility in some cider cultivars may require replacement of the traditional harvesting and postharvest handling procedures.

Content of polyphenols in cider apples is of utmost importance; while procyanidins are the only true tannins, other phenolic compounds can act as precursors for cider aroma (Lea, 1995; Wojdylo, 2008). Moreover, human health effects have been indicated for some phenolic compounds in apple like phloridzin (Schulze et al., 2014). A thorough screening of the chemical contents of cider apple cultivars could therefore be used as a basis for developing more healthy beverages.

A suitable level of acidity is required to obtain sufficient flavour and to avoid bacterial infection during the fermentation. To ensure sufficient fermentation, a comparatively high sugar content is also desirable. Most craft ciders are produced from a careful blend of cider and dessert cultivars, which together offer the desired levels of tannins, acid and sugar.

Chemical content in dessert apple is affected by various environmental factors like orchard location and management (Tahir and Nybom, 2013). A similar environmental impact is expected for cider apples. In a recent trial with four English cider cultivars in Washington, USA, chemical content was compared to data obtained for the same cultivars when previously grown at Long Ashton in England (Alexander et al., 2016). Amount of tannins in the Washington-produced juice was almost halved compared to that in England, possibly due to differences in, e.g., rootstock, pruning, irrigation and fertilization. In addition, significant year-by-year variation in the Washington orchards could be attributed to weather conditions.

Part of the fruit yield is usually lost during harvest and storage due to fungal diseases like blue mould, Penicillium expansum (Pianzzola et al., 2004). Commonly, harvesting in cider apple orchards consists of allowing the fruit to drop to the ground - sometimes after vigorous shaking of the trees. This procedure results in numerous potential entry points 
for the blue mould fungus. This fungus also produces the mycotoxin patulin (Pitt and Hocking, 2009), which is harmful to humans but appears not to survive fermentation processes and is usually not found in alcoholic cider. Possible toxicity of its breakdown products has not yet been determined.

Post-harvest spraying of fruit is no longer allowed in some countries in Europe and fungicides are completely prohibited in organic orchards. Overly susceptible cultivars therefore need to be replaced. Late-ripening dessert apple cultivars, with an above-average fruit firmness at harvest and a below-average rate of fruit softening during storage, are comparatively tolerant to blue mould (Ahmadi-Afzadi et al., 2013). In addition, phenolic compounds, such as flavonols and procyanidin $\mathrm{B} 2$, may protect the fruit from fungal decay (Ahmadi-Afzadi et al., 2015). Since late-ripening, relatively firm fruit and high levels of polyphenols are characteristics found in most cider apples, these may be hypothesized to have good tolerance to blue mould.

An observation trial with two-year old trees was planted in 2014 at Balsgård, Department of Plant Breeding, SLU in Sweden, in order to determine whether English and French cider apple cultivars are sufficiently adapted for use in commercial orchards in South Sweden. In the present study, chemical contents were examined in 2016 on fruit harvested in this trial as well as in a commercial Swedish cider apple orchard planted in 2012-2013, amounting to a total of 19 cider apple cultivars. Five dessert apple cultivars, growing at Balsgård, were included for comparison. In addition, fruit firmness and susceptibility to $P$. expansum was investigated in a subset of 10 cultivars ( 5 cider cultivars and 5 dessert cultivars) in 2016. For 8 of these, investigations were repeated in 2017.

The major aims were (1) to investigate whether fruit quality in Swedish-grown cider cultivars is similar to the quality obtained in the countries of origin, (2) to investigate whether cider cultivars differ from dessert cultivars in overall susceptibility to blue mould, and (3) to elucidate possible associations between disease symptoms and various chemical and fruit quality factors.

\section{Materials and methods}

\section{Cultivars, harvesting and fresh fruit quality}

Fruit from 10 cider cultivars and 5 dessert cultivars (Table 1) was harvested from the orchards at Balsgård in Southern Sweden $\left(56^{\circ} 06^{\prime} \mathrm{N} ; 4^{\circ} 09^{\prime} \mathrm{E}\right)$. Fruit from 9 cider cultivars (one of which was identical to a cultivar sampled at Balsgård but the two accessions are treated as unique cultivars in this study) was obtained from MarkCider in Misterhult, Southeastern Sweden $\left(57^{\circ} 27^{\prime} \mathrm{N}, 16^{\circ} 36^{\prime} \mathrm{E}\right)$. Conventional fertilization and trickle irrigation was used. The orchards at Balsgård are maintained like a commercial low-input orchard, including 5 to 6 applications of fungicides in spring and summer, the last spraying applied in the beginning of July. The orchards at MarkCider did not receive any fungicides. Trees of the cider apple cultivars were grafted on rootstocks MM106 or MM111, planted in 2012-2015, and trained and pruned as a central leader tree (Balsgård) or a bush tree (MarkCider). Dessert apple trees were grafted on M26 ('Elise', 'Ingrid Marie', 'Luke') or MM106 ('Bersis', 'Olga'), and planted in 19962004.

At Balsgård fruit was picked at commercial harvest time from 15 September to 12 October 2016 (Table 1). Fruit from five Long Ashton cultivars ('Angela', 'Jane', 'Lizzy', 'Prince William', 'Three Counties') was harvested separately from each of 6 to 10 trees per cultivar. Fruit from 3 trees per cultivar were used for juice pressing to investigate variation in chemical parameters between trees. The rest of the fruit was pooled and used in the P. expansum experiment described below. For the remaining cultivars harvested at Balsgård, fruit was picked from only one or two trees per cultivar and pooled. At Balsgård, the iodine starch test (Smith et al., 1979) was used to determine commercial harvest time (values 4-5 on a 10 point scale). Cultivars grown at MarkCider were overall more late-ripening compared to the cultivars at Balsgård, and were therefore not harvested until the $11^{\text {th }}$ of October 2016; fruit was pooled from two or three trees per cultivar. Local climate at MarkCider is very mild for its latitude, and the two samples of 'Harry Masters Jersey' were harvested on consecutive days (Oct. 11 at MarkCider and Oct. 12 at Balsgård), suggesting that there was little difference in climatic conditions between the two orchards.

In 2017, fruit from 1-3 trees of the five cider cultivars 'Angela', 'Jane', 'Lizzy', 'Prince William', 'Three Counties', and the three dessert apple cultivars 'Elise', 'Bersis', 'Olga', was picked at Balsgård at commercial harvest time and used in the chemical analyses (only 'Angela' and 'Jane') and in the P. expansum experiment described below.

Ten fruits from each of 10 cultivars (the Long Ashton cider cultivars 'Angela', 'Jane', 'Lizzy', 'Prince William', 'Three Counties' and the dessert cultivars 'Elise', 'Ingrid Marie', 'Luke', 'Bersis', 'Olga') were selected in 2016 to determine firmness at harvest using a penetrometer (model FT-327, Effigy, Alfonsine, Italy, plunger diameter $11.1 \mathrm{~mm}$, depth $7.9 \mathrm{~mm}$ ) at opposite peeled sides of the fruit. After storage at $2^{\circ} \mathrm{C}$ for 8 weeks in normal atmosphere, firmness was determined in another 10 fruits to calculate rate of softening (firmness at harvest minus firmness after storage). In 2017, firmness was determined in the same way on the eight cultivars harvested.

\section{Chemical analyses}

Five fruits were taken from each harvested sample for chemical analyses (Table 1). Three samples (one per individual tree) were made from 5 Long Ashton cultivars ('Angela', 'Jane', 'Lizzy', 'Prince William', 'Three Counties') to investigate variation between trees, whereas only one sample per cultivar was taken for the remainder. Fruits were washed with tap water and processed into juice and pulp using a Frutty ${ }^{\odot}$ soft press (Frutty, Germany). 50 mL juice and circa 100 g pulp per sample were stored separately in a freezer until all cultivars were harvested and processed. For pulp samples, 5 g pulp was diluted using $20 \mathrm{~mL}$ distilled water and homogenized with a PT-10-OD Polytron Homogenizer (Luzern, Switzerland). For juice samples no homogenization was required.

Soluble Solids Content (SSC, roughly equivalent to amount of sugar) was measured in all juice and pulp samples with a refractometer (HI 96801, Hanna, USA). To determine total titratable acidity (TTA) of juice, $5 \mathrm{~g}$ was titrated with $0.1 \mathrm{M} \mathrm{NaOH}$ to a $\mathrm{pH}$ of 8.4 using a SAC-80 automated titration device controlled by a TIM-90 titration controller (Radiometer Analytical Inc., Copenhagen, Denmark). For pulp samples, $2 \mathrm{~g}$ homogenized product was titrated with $0.01 \mathrm{M} \mathrm{NaOH}$ as described above. All samples were analysed in duplicates.

Total phenol (TPH) and HPLC analysis required further extraction: $5 \mathrm{~mL}$ juice or $5 \mathrm{~g}$ homogenized pulp was mixed with $5 \mathrm{~mL}$ extraction fluid containing ethanol with $6.76 \mathrm{~mL}$ $\mathrm{H}_{3} \mathrm{PO}_{4}$ per liter. Pulp samples were centrifuged $30 \mathrm{~min}$ at 4,000 rpm and the clear phase was extracted. Juice samples were centrifuged $15 \mathrm{~min}$ at the same speed to separate par- 
TABLE 1. Name and location ( $B$ = Balsgård, $M$ = MarkCider), harvest date, SSC (soluble solids content, \%), TTA (total titratable acid, \%) and TPH (total phenols, $\mathrm{mg} \mathrm{g}^{-1} \mathrm{GAE}$ ) in fruit juice and pulp for samples of 24 apple cultivars analysed in 2016 in this study. Analyses of variance for variation between cultivars.

\begin{tabular}{|c|c|c|c|c|c|c|c|}
\hline \multirow{2}{*}{ Cultivar } & \multirow{2}{*}{ Harvest date } & \multicolumn{2}{|c|}{ SSC } & \multicolumn{2}{|c|}{ TTA } & \multicolumn{2}{|c|}{ TPH } \\
\hline & & Juice & Pulp & Juice & Pulp & Juice & Pulp \\
\hline Angela, B & $28-09-2016$ & 11.9 & 1.7 & 0.94 & 0.18 & 2.43 & 18.30 \\
\hline Bersis* ${ }^{*}$ B & $23-09-2016$ & 10.3 & 1.8 & 0.71 & 0.16 & 0.97 & 6.20 \\
\hline Brown Snout, M & $11-10-2016$ & 15.9 & 2.3 & 0.36 & 0.06 & 3.32 & 12.98 \\
\hline Brown's Apple, M & $11-10-2016$ & 14.2 & 2.5 & 0.79 & 0.16 & 1.21 & 18.05 \\
\hline Dabinett, M & $11-10-2016$ & 15.0 & 2.1 & 0.14 & 0.02 & 2.14 & 22.40 \\
\hline Elise $^{*}, \mathrm{~B}$ & $23-09-2016$ & 9.8 & 1.6 & 0.59 & 0.12 & 0.29 & 15.24 \\
\hline Fiona, B & 03-10-2016 & 14.0 & 2.3 & 0.83 & 0.16 & 4.42 & 25.38 \\
\hline Foxwhelp, M & 01-10-2016 & 12.6 & 2.2 & 1.71 & 0.31 & 4.00 & 20.79 \\
\hline Frederick, M & $11-10-2016$ & 14.4 & 2.6 & 1.43 & 0.30 & 0.47 & 18.58 \\
\hline Frequin Rouge, B & $12-10-2016$ & 10.7 & 1.5 & 0.29 & 0.04 & 4.40 & 18.46 \\
\hline Harry Masters, B & $12-10-2016$ & 14.1 & 2.3 & 0.29 & 0.04 & 4.64 & 16.72 \\
\hline Harry Masters, M & $11-10-2016$ & 15.8 & 2.4 & 0.32 & 0.04 & 2.18 & 16.16 \\
\hline Ingrid Marie*, B & 03-10-2016 & 12.0 & 2.1 & 0.85 & 0.17 & 1.01 & 29.37 \\
\hline Jane, B & $23-09-2016$ & 11.3 & 1.9 & 0.21 & 0.08 & 3.61 & 19.61 \\
\hline Judeline, B & $12-10-2016$ & 14.3 & 2.8 & 1.07 & 0.20 & 1.32 & 24.85 \\
\hline Kingston Black, B & $12-10-2016$ & 12.6 & 2.4 & 0.50 & 0.10 & 1.65 & 13.34 \\
\hline Lizzy, B & $28-09-2016$ & 11.6 & 2.0 & 0.44 & 0.05 & 1.69 & 18.77 \\
\hline Luke $^{*}, \mathrm{~B}$ & $15-09-2016$ & 10.0 & 1.5 & 1.34 & 0.25 & 2.47 & 19.21 \\
\hline Olga* B & $07-10-2016$ & 10.6 & 1.8 & 0.57 & 0.12 & 0.69 & 7.58 \\
\hline Prince William, B & 03-10-2016 & 13.8 & 2.2 & 0.19 & 0.04 & 2.18 & 18.16 \\
\hline Sweet Alford, M & $11-10-2016$ & 15.0 & 2.6 & 0.25 & 0.05 & 1.56 & 8.66 \\
\hline Three Counties, B & 07-10-2016 & 13.6 & 1.8 & 0.23 & 0.04 & 3.27 & 19.49 \\
\hline Vilberie, M & $11-10-2016$ & 14.4 & 2.4 & 0.32 & 0.05 & 2.35 & 30.27 \\
\hline Yarlington Mill, M & $11-10-2016$ & 16.0 & 2.7 & 0.30 & 0.05 & 1.45 & 19.99 \\
\hline F-value & & 62.98 & 4.05 & 36.67 & 115.61 & 67.70 & 14.23 \\
\hline df & & $23 / 44$ & $23 / 44$ & $23 / 44$ & $23 / 44$ & $23 / 112$ & $23 / 112$ \\
\hline P-value & & $<0.001$ & $<0.001$ & $<0.001$ & $<0.001$ & $<0.001$ & $<0.001$ \\
\hline
\end{tabular}

* Dessert cultivar, remainder are cider cultivars.

ticles and the clear fluid was extracted. The Folin-Ciocalteu method (Singleton et al., 1999) was used to analyse the total phenol content. In summary $10 \mu \mathrm{L}$ of juice sample was diluted to a volume of $100 \mu \mathrm{L}$ with distilled water in a cuvette. $200 \mu \mathrm{L}$ Folin-Ciocalteu reagent was added followed by $2 \mathrm{~mL} 15 \% \mathrm{Na}_{2} \mathrm{CO}_{3}$ and $1 \mathrm{~mL}$ distilled water. The contents of the cuvette were mixed and then incubated for $1 \mathrm{~h}$ at room temperature. A UV-2101PC spectrophotometer (Shimadzu, Kyoto, Japan) measured the absorbance at $765 \mathrm{~nm}$ in duplicate for each sample. Total phenols content was expressed as mg GAE (gallic acid equivalents) per gram of fresh weight. All samples were run in $2 \times 2$ replicates, resulting in twelve values per cultivar for the 5 Long Ashton cultivars (for which fruit from three trees were analysed separately) and four values for the remaining cultivars.

Single phenolic compounds were analysed and quantified using HPLC-MS consisting of a Sciex API 150EX Turbo ion spray mass spectrometer with a Perkin-Elmer 200 auto sampler and two Perkin Elmer LC-200 micro pumps. Separations were achieved using a Phenomenex AQ C18 $(4 \times 3.0 \mathrm{~mm})$ guard column, and a Phenomenex Synergi $4 \mu \mathrm{m}$ Hydro-RP $80 \AA(250 \times 4.6 \mathrm{~mm})$ column. The mobile phase consisted of $1 \%(\mathrm{v} / \mathrm{v})$ acetic acid with $5 \%$ acetonitrile $(\mathrm{v} / \mathrm{v})$ in water (Solvent A) and 95\% acetonitrile with 5\% methanol (Solvent B). A linear gradient program was used as follows: from $0-2 \mathrm{~min}$, isocratic $2 \% \mathrm{~B}$; from $2-8 \mathrm{~min}$, a gradient to $15 \% \mathrm{~B}$; from $8-28 \mathrm{~min}$, a gradient to $21 \% \mathrm{~B}$; from $28-32 \mathrm{~min}$, a gradient to $80 \% \mathrm{~B}$; from $32-36 \mathrm{~min}$, isocratic $80 \% \mathrm{~B}$; from 36-37 min, a gradient back to $2 \% \mathrm{~B}$; and from $37-42 \mathrm{~min}$, isocratic $2 \%$ (total run time was $42 \mathrm{~min}$ ). The injection volume was $4 \mu \mathrm{L}$ for all samples and the flow rate was kept at $1 \mathrm{~mL} \mathrm{~min}^{-1}$. Regardless of the eluent, it was split to $0.3 \mathrm{~mL}$ $\mathrm{min}^{-1}$ before the IonSpray unit. The general conditions were: nebulizer gas (nitrogen), $9.0 \mathrm{~L} \mathrm{~min}^{-1}$; curtain gas, $12.0 \mathrm{~L} \mathrm{~min}^{-1}$; IonSpray voltage, $-4,000$; temperature, $300^{\circ} \mathrm{C}$. The mass spectrometer was operated in a negative mode and a scan range of 125-1,500 atomic mass units (amu) was used. Mass numbers $\left.(\mathrm{m} / \mathrm{z}[\mathrm{M}-\mathrm{H}]]^{-}\right)$for detected ions was as follows: catechin (CAT, 289.0), chlorogenic acid (CHL, 353.1), epicatechin (EPI, 289.0), phloretin pentosylhexoside (PHP, 567.1), phloridzin (PHL, 435.3), procyanidin B2 (PB2, 577.1) and trimer aglycone (TAG, 865.1). For quantification a standard curve was used for each of five external standards (CAT, CHL, EPI, PHL and PB2). PHP was quantified according to the PHL standard while TAG was quantified according to the PB2 standard. A standard mix was also injected at the beginning of the run and after every 10 samples to ensure inter- and intra-day precision. Samples were run in duplicate. Standard deviation was calculated for each technical duplicate and the analysis was repeated if needed. 
In 2017, SSC, TTA and TPH was measured as above in juice of 'Angela' and 'Jane' to provide a comparison between years.

\section{Inoculation with $P$. expansum}

Blue mould was isolated from naturally infected apples showing typical disease symptoms. Mycelium was maintained on petri dishes with potato dextrose agar augmented with penicillin $\mathrm{G}$ and streptomycin sulphate (each at $200 \mathrm{mg}$ $\mathrm{L}^{-1}$ agar), and stored separately as pure cultures at $4^{\circ} \mathrm{C}$. Spores from 10-day-old cultures were removed and suspended in $5 \mathrm{~mL}$ sterile distilled water containing $0.05 \%(\mathrm{v} / \mathrm{v})$ Tween 80. The suspension was filtered and the concentration of spores was adjusted to $1 \times 10^{5}$ conidia $\mathrm{mL}^{-1}$.

Inoculations were carried out on fruit of five Long Ashton cider cultivars ('Angela', 'Jane', 'Lizzy', 'Prince William', 'Three Counties') and five dessert cultivars ('Elise', 'Ingrid Marie', 'Luke', 'Bersis', 'Olga') in 2016. Within three days after harvest, the fruits were rinsed with tap water to remove most of the naturally occurring fungi, wiped dry and then wounded with a pipette point to a depth of circa $4 \mathrm{~mm}$ on two opposite sides of the fruit. $20 \mu \mathrm{L}$ of spore solution was deposited in these wounds with a pipette. Three replicates of 15 fruits each were inoculated with the spore solution and 10 control fruits were inoculated with $20 \mu \mathrm{L}$ sterile distilled water. After inoculation, fruits were stored in open-faced plastic boxes at $2^{\circ} \mathrm{C}$ for eight weeks. Lesion diameter was measured in millimeters to determine the severity of the infection after storage. In 2017, inoculations were performed in the same way on the same set of cultivars, except for 'Luke' and 'Ingrid Marie' where fruit was not available.

\section{DNA analyses}

In the Long Ashton breeding program, pollen of the dessert apples 'James Grieve' and 'Worcester Pearmain' was used to fertilize traditional cider apples 'Dabinett' and 'Michelin' (Copas, 2010). In order to determine the exact parentage of each of the six Long Ashton cultivars included in this study ('Angela', 'Fiona', 'Jane', 'Lizzy', 'Prince William', 'Three Counties'), fresh leaves of these cultivars and of the four putative parents were used for extraction of DNA with Qiagen Dneasy $^{\mathrm{TM}}$ Plant Mini Kit. Nine SSR primer pairs: CH01h02 (sublocus 2), $\mathrm{CH} 02 \mathrm{c06}, \mathrm{CH} 02 \mathrm{c09}, \mathrm{CH} 02 \mathrm{c} 11, \mathrm{CH} 02 \mathrm{~d} 08, \mathrm{CHO} 4 \mathrm{c06}$ (sublocus 1 and 2), $\mathrm{CHO} 4 \mathrm{e} 02, \mathrm{CH} 04 \mathrm{e} 05$ and $\mathrm{COL}$, were used to amplify 10 loci as previously described (Garkava-Gustavsson et al., 2008). The PCR products were separated and analysed on a 3130xl Genetic Analyzer (Applied Biosystems). Size of the amplified products was determined using an inhouse PCR-based standard, and evaluated with GeneMarker software version 1.85 (SoftGenetics). All obtained DNA profiles were compared manually, and parentage was determined based on allele-sharing in each locus.

\section{Statistical analyses}

Analyses of variance (ANOVA) were used to determine variation within and between cultivars for lesion diameter, firmness and softening, and chemical contents. Cultivars were separated post hoc for the first-mentioned three parameters using Tukey's HSD. There was no significant variation in any parameter among biological replicates (three different trees harvested) from the same cultivar, and therefore cultivar means were used in all further calculations. Hierarchical clustering was performed on the chemical data and on the DNA marker data, respectively, to group the cultivars in a dendrogram using average linkage and Euclidean distanc- es. Pearson correlation tests were carried out to determine associations between lesion diameter and the other parameters. Principal components analysis was used to investigate the relationship between cultivars and between parameters. Statistical tests were carried with SPSS 21 (IBM SPSS Statistics for Windows, Version 21.0. Armonk, NY, 2012).

\section{Results}

\section{Variation in chemical contents}

Sugar content (SSC) ranged from $9.8{ }^{\circ}$ Brix $(=\%$ in weight) in 'Elise' to 16.0 in 'Yarlington Mill' in the juice samples, and from 1.5 in 'Frequin Rouge' and 'Luke', to 2.8 in 'Judeline' in the pulp samples (Table 1). Analysis of variance confirmed significant variation in SSC between cultivars for both juice $(\mathrm{F}=69.98, \mathrm{df}=23 / 44, \mathrm{p}<0.001)$ and pulp $(\mathrm{F}=4.05$, $\mathrm{df}=23 / 44, \mathrm{p}<0.001)$. Cider cultivars had overall higher SSC both in juice and pulp (13.7 and 2.2, respectively) compared to dessert apples (10.5 and 1.8, respectively). For the two cultivars analysed in both years, SSC in juice of 'Angela' was 11.9 in 2016 and 14.15 in 2017, while SSC in juice of 'Jane' was 11.3 and 16.3, showing considerable variation between years.

The most extreme values for acidity (TTA) were noted for two traditional English cider apples; 'Dabinett' with 0.14\% in juice and $0.02 \%$ in pulp, and 'Foxwhelp' with $1.71 \%$ in juice and $0.31 \%$ in pulp. Analysis of variance showed that variation between cultivars was highly significant in both juice $(\mathrm{F}=36.67, \mathrm{df}=23 / 44, \mathrm{p}<0.001)$ and pulp $(\mathrm{F}=115.61$, $\mathrm{df}=23 / 44, \mathrm{p}<0.001$ ). In spite of considerable overlap, dessert cultivars had a higher mean TTA than the cider cultivars, in juice $0.81 \%$ and $0.56 \%$ in dessert and cider cultivars, respectively) as well as in pulp $(0.16 \%$ and $0.10 \%$ in dessert and cider cultivars, respectively). TTA values for 'Angela' were 0.94 in 2016 and 0.95 in 2017, while values for 'Jane' were 0.21 and 0.24 , indicating high stability between years. Data obtained in our study was highly correlated with data previously reported from Long Ashton (Lea, http://www. cider.org.uk) and Copas (2010) for 10 of the cider cultivars; $\mathrm{r}=0.948, \mathrm{df}=9, \mathrm{p}<0.001$ ) but mean values were somewhat higher in Sweden; 0.56 compared to 0.47 in England.

The highest total phenols content (TPH) in juice was found in the traditional English cider cultivar 'Harry Masters Jersey' (sample collected at Balsgård) (4.64 mg GAE g-1) while the lowest was obtained in the dessert cultivar 'Elise' (0.29). Pulp had an almost tenfold higher content of phenols reaching $30.27 \mathrm{mg} \mathrm{GAE} \mathrm{g}^{-1}$ in the traditional French cider cultivar 'Vilberie' while the dessert cultivar 'Bersis' had the lowest (6.20). ANOVA confirmed significant variation between cultivars in both juice $(\mathrm{F}=67.79, \mathrm{df}=23 / 112, \mathrm{p}<0.001)$ and pulp $(\mathrm{F}=14.23, \mathrm{df}=23 / 112, \mathrm{p}<0.001)$. Cider cultivars had, as expected, considerably higher TPH in juice (2.54) and pulp (18.13) compared to the dessert cultivars (1.09 in juice, 15.52 in pulp), but two of the dessert apples showed surprisingly high values; 'Luke' in juice (2.47) and 'Ingrid Marie' in pulp (29.37). Data obtained in our study were not correlated with data previously reported for cider cultivars in England (Lea, http://www.cider.org.uk; Copas, 2010), but mean values were still similar; 2.37 in the Balsgård analyses and 2.44 in the analyses carried out in England.

Data obtained for TPH in 2016 ('Angela' 2.43 and 'Jane' 3.61) and 2017 ('Angela' 2.84 and 'Jane' 3.07), suggest that values were relatively stable across years.

Seven different phenolic compounds were quantified in juice, including flavanols (PB2, CAT, EPI), proanthocyanidin 
TABLE 2. Fruit juice content of separately determined phenolic compounds; CHL (chlorogenic acid), PB2 (procyanidin B2), CAT (catechin), EPI (epicatechin), TAG (trimer aglycone), PHL (phloridzin) and PHP (phloretin pentosylhexoside), all in $\mathrm{mg} \mathrm{mL}^{-1}$. Analyses of variance for variation between cultivars.

\begin{tabular}{|c|c|c|c|c|c|c|c|}
\hline Cultivars & $\mathrm{CHL}$ & PB2 & CAT & EPI & TAG & $\mathrm{PHL}$ & PHP \\
\hline Angela & 0.100 & 0.087 & 0.004 & 0.103 & 0.034 & 0.014 & 0.135 \\
\hline Bersis* & 0.126 & 0.005 & 0.008 & 0.020 & 0.005 & 0.002 & 0.011 \\
\hline Brown Snout & 0.963 & 0.047 & 0.022 & 0.141 & 0.023 & 0.020 & 0.024 \\
\hline Brown's Apple & 0.373 & 0.000 & 0.006 & 0.018 & 0.003 & 0.006 & 0.033 \\
\hline Dabinett & 0.672 & 0.240 & 0.024 & 0.298 & 0.114 & 0.057 & 0.065 \\
\hline Elise* & 0.082 & 0.001 & 0.001 & 0.002 & 0.003 & 0.002 & 0.022 \\
\hline Fiona & 0.412 & 0.268 & 0.008 & 0.275 & 0.110 & 0.010 & 0.047 \\
\hline Foxwhelp & 0.771 & 0.010 & 0.003 & 0.017 & 0.007 & 0.025 & 0.118 \\
\hline Frederick & 0.208 & 0.025 & 0.002 & 0.000 & 0.022 & 0.000 & 0.033 \\
\hline Frequin Rouge & 0.876 & 0.130 & 0.032 & 0.212 & 0.064 & 0.099 & 0.113 \\
\hline Harry Masters B & 0.321 & 0.188 & 0.031 & 0.364 & 0.102 & 0.008 & 0.039 \\
\hline Harry Masters M & 0.664 & 0.298 & 0.046 & 0.434 & 0.159 & 0.012 & 0.049 \\
\hline Ingrid Marie* & 0.102 & 0.033 & 0.026 & 0.062 & 0.012 & 0.004 & 0.023 \\
\hline Jane & 0.345 & 0.109 & 0.007 & 0.203 & 0.047 & 0.006 & 0.080 \\
\hline Judeline & 0.071 & 0.047 & 0.006 & 0.061 & 0.020 & 0.007 & 0.038 \\
\hline Kingston Black & 0.486 & 0.019 & 0.003 & 0.037 & 0.008 & 0.005 & 0.056 \\
\hline Lizzy & 0.217 & 0.044 & 0.011 & 0.110 & 0.021 & 0.006 & 0.050 \\
\hline Luke* & 0.834 & 0.021 & 0.016 & 0.050 & 0.009 & 0.014 & 0.048 \\
\hline Olga* & 0.134 & 0.008 & 0.010 & 0.038 & 0.003 & 0.008 & 0.012 \\
\hline Prince William & 0.480 & 0.064 & 0.012 & 0.119 & 0.024 & 0.005 & 0.052 \\
\hline Sweet Alford & 0.560 & 0.006 & 0.023 & 0.052 & 0.006 & 0.006 & 0.016 \\
\hline Three Counties & 0.397 & 0.125 & 0.011 & 0.175 & 0.056 & 0.006 & 0.042 \\
\hline Vilberie & 1.149 & 0.390 & 0.045 & 0.570 & 0.203 & 0.009 & 0.108 \\
\hline Yarlington Mill & 1.160 & 0.062 & 0.108 & 0.188 & 0.012 & 0.011 & 0.047 \\
\hline F-value & 118.40 & 61.35 & 83.03 & 86.36 & 69.87 & 120.66 & 33.58 \\
\hline$d f$ & $23 / 44$ & $23 / 44$ & $23 / 44$ & $23 / 44$ & $23 / 44$ & $23 / 44$ & $23 / 44$ \\
\hline P-value & $<0.001$ & $<0.001$ & $<0.001$ & $<0.001$ & $<0.001$ & $<0.001$ & $<0.001$ \\
\hline
\end{tabular}

* Dessert cultivars, remainder are cider cultivars.

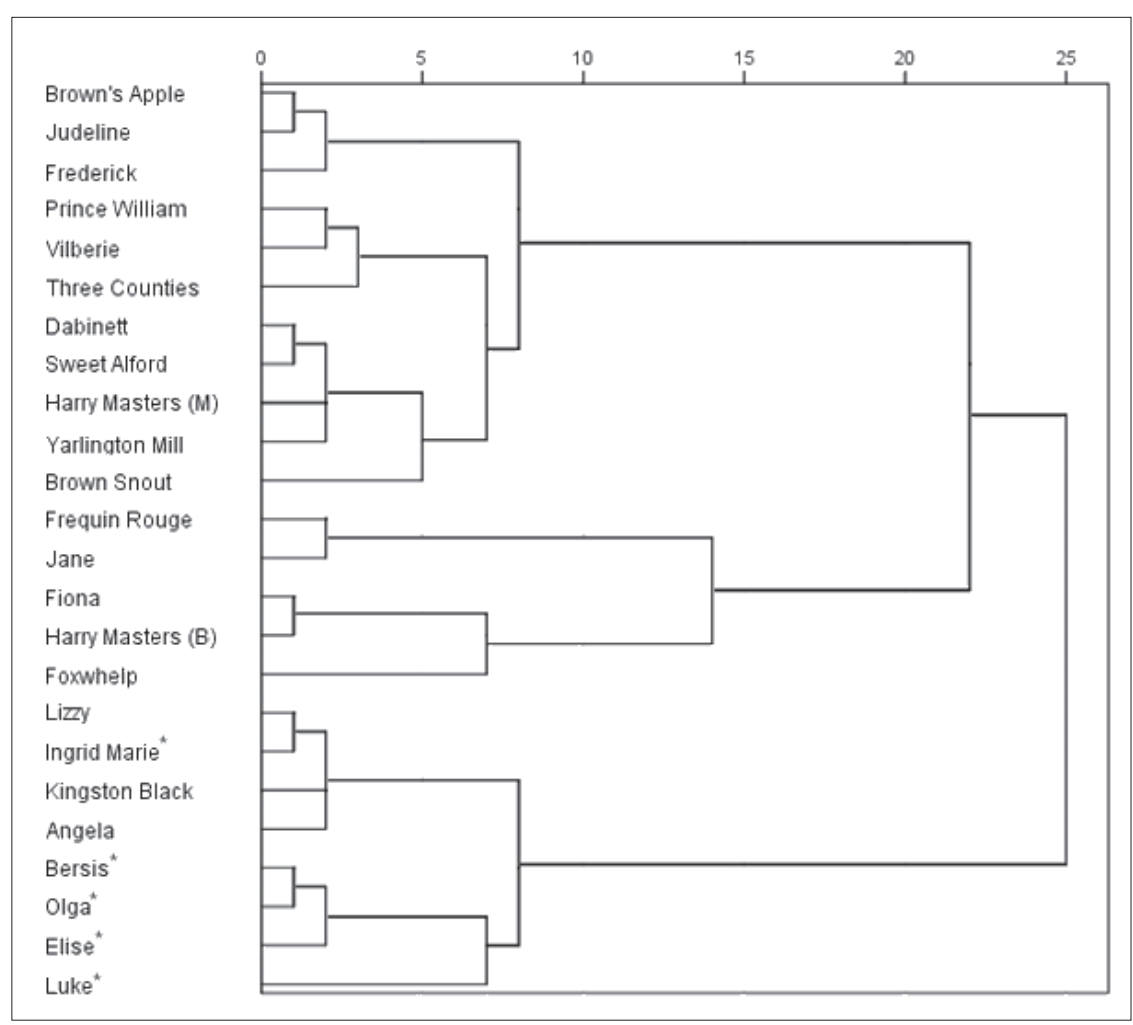

FigURE 1. Dendrogram based on chemical data (SSC, TTA, TPH and 7 separately determined phenolic compounds) derived from fruit juice analyses in 19 cider cultivars and 5 dessert cultivars $\left(^{*}\right)$. 
(TAG), hydroxycinnamic acids (CHL) and dihydrochalcones (PHL, PHP) (Table 2). Analysis of variance showed significant variation between cultivars for all measured phenolic compounds. Chlorogenic acid (CHL) had the highest concentration. Cider apples and dessert apples differed considerably for some compounds; concentration of procyanidin B2 (PB2) was 6.5 times higher in cider cultivars compared to dessert cultivars, while epicatechin (EPI) was 4.1 times higher. Consistently very low values for all 7 compounds were noted for the dessert cultivar 'Elise' while comparatively low values were found for two other dessert cultivars, 'Bersis' and 'Olga', as well as for the cider cultivars 'Brown's Apple' and 'Frederick'.

A dendrogram based on chemical data derived from the juice samples (SSC, TTA, TPH and the 7 individually determined compounds) shows that the 5 dessert cultivars form one major group together with the cider cultivars 'Lizzy', 'Kingston Black' and 'Angela' (all of which have unusually low SSC values for being cider apples), while the remaining cider cultivars form the other major group (Figure 1). The Long Ashton cultivars are widely spread out in the dendrogram although 'Lizzy' and 'Angela' group together, as do also 'Prince William' and 'Three Counties'.

\section{Classification of cider cultivars}

Acidity is usually estimated by titration with a base, producing data that can be compared across studies. The commonly acknowledged cut-off point is 0.45 ; cider cultivars with a higher acidity are termed 'sharp' and those below are termed 'sweet' (Copas, 2010).

Tannin contents of apple juice or cider (usually similar since fermentation has little impact on tannin content) have traditionally been estimated by titration with potassium permanganate and an indigo carmine indicator, yielding data expressed as \% arbitrary tannic acid equivalents. By contrast, present-day studies use Folin-Ciocalteu chromatography with data expressed as mg gallic acid equivalents $\mathrm{g}^{-1}$ fresh weight. These two methods have been shown to yield almost identical data when applied to the same juice or cider (Lea, http://www.cider.org.uk). Therefore, the cut-off point between bitter and non-bitter cultivars is usually defined as $0.20 \%$ (or $2.0 \mathrm{mg} \mathrm{GAE}^{-1}$ ) regardless of method.

Classification of the 19 cider cultivars conformed to previous reports except for two cultivars; 'Lizzy' and 'Yarlington Mill', which had somewhat lower TPH values in our investigation compared to what has been found in previous studies and therefore fell into sweet instead of bittersweet (Table 1). In addition, 'Kingston Black' which has previously been regarded both as sharp and as bittersharp, was classified as sharp in the present study. A PCA was calculated based on the chemical data (SSC, TTA, TPH and the 7 different phenolic compounds) obtained in juice samples of all investigated cider cultivars. The first two components explained 69.5\% of the variance. Grouping of the cultivars in the PCA corresponded roughly to the four commonly acknowledged cider apple classification groups (Figure 2). Interestingly, the 5 Long Ashton cultivars now grouped closely together.

\section{Fruit firmness and susceptibility towards blue mould}

Firmness at harvest and after storage was measured on fruit from 10 cultivars in 2016 (Table 3). Firmness at harvest (expressed as the mean of 10 investigated fruits) was lowest for 'Ingrid Marie' and 'Prince William' (6.6 and $8.2 \mathrm{~kg} \mathrm{~cm}^{-2}$, respectively) while 'Bersis' and 'Angela' had the firmest fruits

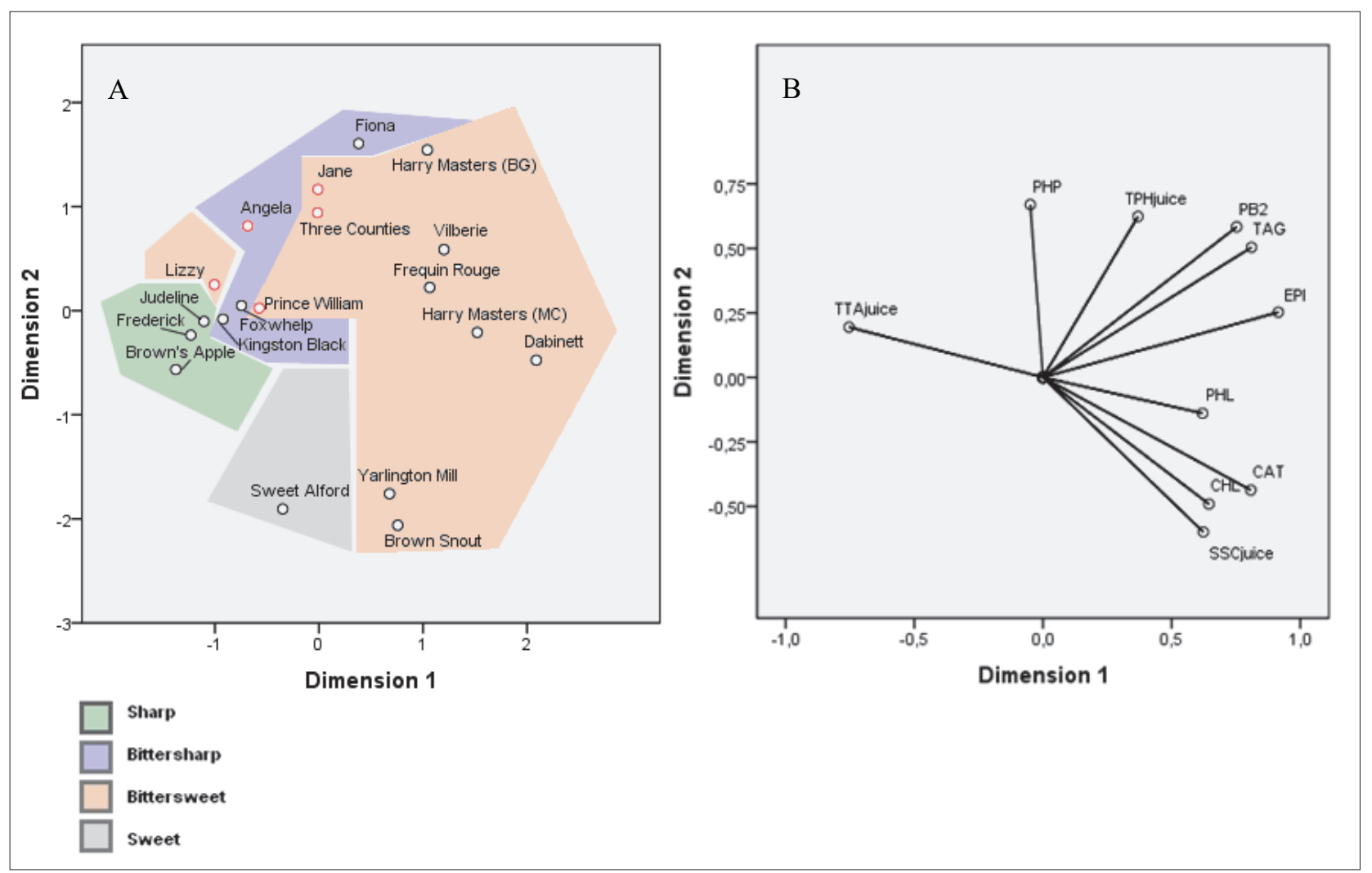

FigURE 2. PCA based on chemical data (SSC, TTA, TPH and 7 separately determined phenolic compounds) derived from fruit juice analyses in 19 cider apple cultivars. Coloured areas correspond to the common classification of these samples into four different cider apple categories. A, Plot of cultivar means. B, Plot of parameter loadings. Red circles: the 5 Long Ashton cultivars used for P. expansum inoculations. Black circles: the remaining cultivars. 
TABLE 3. Lesion diameter ( $\mathrm{mm}$ ) resulting from inoculation with P. expansum spores, fruit firmness at harvest $\left(\mathrm{kg} \mathrm{cm}^{-2}\right)$ and fruit softening (difference between firmness at harvest and firmness after 8 weeks of storage) in 2016. Values that have the same letter do not differ $(\mathrm{p}<0.05)$ according to Tukey's HSD.

\begin{tabular}{|c|c|c|c|}
\hline Cultivar & Lesion diameter & Firmness at harvest & Softening \\
\hline Angela & $39.1 \mathrm{c}$ & $12.5 \mathrm{e}$ & $4.5 \mathrm{~cd}$ \\
\hline Bersis* & $17.6 \mathrm{a}$ & $11.4 \mathrm{de}$ & $0 \mathrm{a}$ \\
\hline Elise* & $22.6 \mathrm{a}$ & $10.2 \mathrm{~cd}$ & $2.1 \mathrm{ab}$ \\
\hline Ingrid Marie* & $32.1 \mathrm{~b}$ & $6.6 \mathrm{a}$ & $1.9 \mathrm{ab}$ \\
\hline Jane & $37.8 \mathrm{c}$ & $8.4 b$ & $1.4 \mathrm{a}$ \\
\hline Lizzy & $46.4 d$ & $8.3 b$ & $2.4 a b$ \\
\hline Luke* & $28.5 b$ & $8.6 \mathrm{~b}$ & $2.0 \mathrm{ab}$ \\
\hline Olga* & $20.3 a$ & $9.0 \mathrm{bc}$ & $3.2 \mathrm{bc}$ \\
\hline Prince William & $46.2 \mathrm{~d}$ & $8.2 b$ & $4.9 \mathrm{~d}$ \\
\hline Three Counties & $39.4 \mathrm{c}$ & $9.3 \mathrm{bc}$ & $0.8 \mathrm{a}$ \\
\hline F-value & 85.11 & 37.20 & 14.59 \\
\hline$d f$ & $9 / 440$ & $9 / 90$ & $9 / 89$ \\
\hline P-value & $<0.001$ & $<0.001$ & $<0.001$ \\
\hline
\end{tabular}

* Dessert cultivar, remainder are cider cultivars.

TABLE 4. Lesion diameter ( $\mathrm{mm})$ resulting from inoculation with P. expansum spores, fruit firmness at harvest $\left(\mathrm{kg} \mathrm{cm}^{-2}\right)$ and fruit softening (difference between firmness at harvest and firmness after 8 weeks of storage) in 2017. Values that have the same letter do not differ $(\mathrm{p}<0.05)$ according to Tukey's HSD.

\begin{tabular}{lccc}
\hline Cultivar & Lesion diameter & Firmness at harvest & Softening \\
\hline Angela & $37.5 \mathrm{ab}$ & $12.2 \mathrm{~d}$ & $6.3 \mathrm{c}$ \\
Bersis* $^{*}$ & $36.6 \mathrm{ab}$ & $12.6 \mathrm{~d}$ & $1.8 \mathrm{a}$ \\
Elise* $^{*}$ & $11.1 \mathrm{c}$ & $1.8 \mathrm{a}$ \\
Jane & $39.1 \mathrm{~b}$ & $9.1 \mathrm{~b}$ & $2.5 \mathrm{ab}$ \\
Lizzy & $44.0 \mathrm{c}$ & $8.1 \mathrm{a}$ & $2.8 \mathrm{ab}$ \\
Olga* & $45.5 \mathrm{c}$ & $11.1 \mathrm{c}$ & $1.9 \mathrm{a}$ \\
Prince William & $35.4 \mathrm{a}$ & $8.9 \mathrm{ab}$ & $3.6 \mathrm{~b}$ \\
Three Counties & $49.2 \mathrm{~d}$ & $8.7 \mathrm{ab}$ & $2.4 \mathrm{ab}$ \\
\hline F-value & $46.3 \mathrm{~cd}$ & 52.68 & 18.76 \\
df & 45.52 & $7 / 72$ & $7 / 72$ \\
P-value & $7 / 352$ & $<0.001$ & $<0.001$ \\
\hline
\end{tabular}

${ }^{*}$ Dessert cultivar, remainder are cider cultivars.

at $11.4 \mathrm{~kg} \mathrm{~cm}^{-2}$ and $12.5 \mathrm{~kg} \mathrm{~cm}^{-2}$ each. Softening (firmness at harvest minus firmness after storage) was lowest for 'Three Counties' at $0.8 \mathrm{~kg} \mathrm{~cm}^{-2}(8.4 \%)$ loss and 'Jane' with $1.4 \mathrm{~kg} \mathrm{~cm}^{-2}$ (16.5\%) loss. Fruits of 'Bersis', which were relatively firm pre-storage $\left(11.4 \mathrm{~kg} \mathrm{~cm}^{-2}\right)$, became quite rubbery and had a higher penetrometer value after storage $\left(12.0 \mathrm{~kg} \mathrm{~cm}^{-2}\right)$, and therefore softening was given the value zero in the calculations. A one-way ANOVA was conducted and confirmed significant variation between cultivars for both firmness at harvest $(F=37.20, d f=9 / 90, p<0.001)$ and softening $(F=14.59$, $\mathrm{df}=9 / 90, \mathrm{p}<0.001)$. Differences in the analysed parameters showed no association with the division between cider apples and dessert apples.

Fruit of the 10 above mentioned cultivars was also used in the blue mould inoculations of 2016. Of the 100 control fruits (inoculated with water), only one ('Ingrid Marie') had a spontaneous infection, namely Monilinia fructigena. By contrast, artificial inoculation with P. expansum produced lesions on nearly all fruits. Exceptions include one inoculation site each in 'Lizzy' and 'Bersis' along with two sites in 'Luke'. Secondary infection (brown rot and blue mould) occurred in two 'Ingrid Marie' fruits, but the lesions from inoculation could still be scored. A spontaneous infection that overlapped the inoculation site on one of the 'Jane' fruits prohibited scoring on this site. The dessert cultivars 'Bersis' and 'Olga' had the smallest lesions (17.6 and $20.3 \mathrm{~mm}$, respectively) while the cider cultivars 'Prince William' and 'Lizzy' produced the largest lesions (46.2 and $46.4 \mathrm{~mm}$, respectively). Analysis of variance confirmed significant variation between cultivars $(\mathrm{F}=85.11, \mathrm{df}=9 / 440, \mathrm{p}<0.001)$. Cider cultivars had noticeably larger lesions (average $41.8 \mathrm{~mm}$ ) than dessert cultivars (average $24.2 \mathrm{~mm}$ ).

In 2017, fruit firmness, softening during storage, and lesion size after inoculation was measured on 8 of the previously analysed cultivars (Table 4). Differentiation among cultivars was somewhat lower for lesion diameter in 2017 $(\mathrm{F}=45.52, \mathrm{df}=7 / 352, \mathrm{p}<0.001)$ compared to the year before. The difference between cider cultivars (average $44.5 \mathrm{~mm}$ ) and dessert cultivars (average $37.0 \mathrm{~mm}$ ) was smaller, but still four of the cider cultivars had mean values higher than any of the dessert cultivars. 


\section{Associations between lesion diameter and other parameters}

Associations were investigated between fruit texture and chemical parameters on the one hand, and lesion diameter (susceptibility to blue mould) on the other hand, based on 2016 data. Neither firmness at harvest nor softening was correlated with lesion diameter (Table 5). Lesion diameter was positively correlated with sugar content (SSC) in juice $(\mathrm{r}=0.77, \mathrm{df}=8, \mathrm{p}<0.01)$ and almost also with sugar content in pulp $(r=0.60, d f=8, p=0.07)$. Lesion diameter was not significantly correlated with total titratable acidity (TTA) in either juice or pulp, but both analyses were indicative of a negative relationship. Lesion diameter was not significantly correlated with total phenolics (TPH) in either juice or pulp but a positive relationship was indicated $(\mathrm{r}=0.62, \mathrm{df}=8$, $\mathrm{p}=0.054$, and $\mathrm{r}=0.58, \mathrm{df}=8, \mathrm{p}=0.08$, respectively). Three of the individually measured phenolic substances were positively correlated with lesion diameter; procyanidin B2 $(\mathrm{r}=0.70, \mathrm{df}=8, \mathrm{p}<0.05)$, epicatechin $(\mathrm{r}=0.75, \mathrm{df}=8, \mathrm{p}<0.05)$ and trimer aglycone $(r=0.67, \mathrm{df}=8, \mathrm{p}<0.05)$.

PCA was used to reduce the number of variables and present fruit texture (firmness at harvest, softening), chemical (SSC, TTA, TPH and the 7 separately determined phenolic compounds) and lesion data graphically (Figure 3). The first two components explained $79.9 \%$ of the variance. The loading plot shows that TPH, PB2, TAG and EPI were the main contributors to component 1 , which explained up to $56 \%$ of the variation thus being responsible for much of the con-
TABLE 5. Correlations between lesion diameter after inoculation with P. expansum in 2016 on the one hand, and fruit firmness at harvest, fruit softening, SSC (soluble solids content) in juice and pulp, TTA (total titratable acidity) in juice and pulp, TPH (total phenols in juice and pulp), CHL (chlorogenic acid), PB2 (procyanidin B2), CAT (catechin), EPI (epicatechin), TAG (trimer aglycone), PHL (phloridzin) and PHP (phloretin pentosylhexoside) on the other hand.

\begin{tabular}{ll}
\hline Parameter & R-value \\
\hline Firmness at harvest & $-0.28 \mathrm{~ns}$ \\
Fruit softening & $0.44 \mathrm{~ns}$ \\
SSC in juice & $0.77^{* *}$ \\
SSC in pulp & $0.60 \mathrm{~ns}$ \\
TTA in juice & $-0.42 \mathrm{~ns}$ \\
TTAin pulp & $-0.54 \mathrm{~ns}$ \\
TPH in juice & $0.62 \mathrm{~ns}$ \\
TPH in pulp & $0.58 \mathrm{~ns}$ \\
CHL & $0.25 \mathrm{~ns}$ \\
PB2 & $0.70^{*}$ \\
CAT & $0.12 \mathrm{~ns}$ \\
EPI & $0.75^{*}$ \\
TAG & $0.67^{*}$ \\
PHL & $0.20 \mathrm{~ns}$ \\
PHP & $0.58 \mathrm{~ns}$ \\
\hline
\end{tabular}

${ }^{*} 0.05>P>0.01,{ }^{* *} P<0.01$, ns $=$ non-significant.
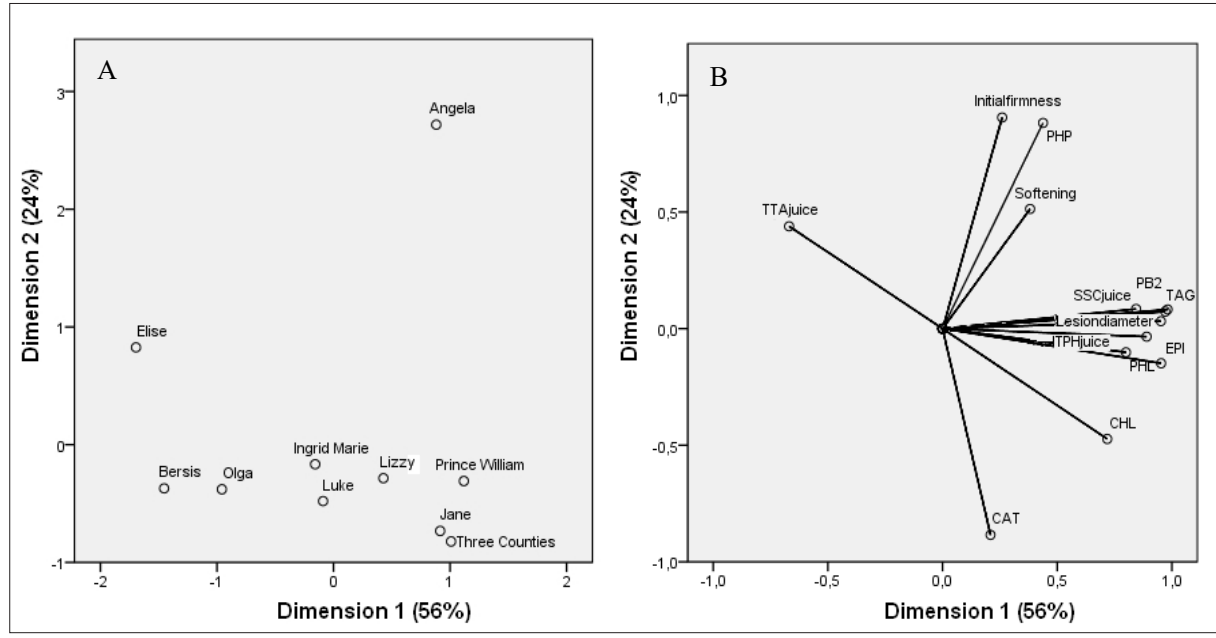

FIGURE 3. PCA based on fruit firmness at harvest, fruit softening, diameter of lesion resulting from inoculation with P. expansum spores, and chemical data (SSC, TTA, TPH and 7 separately determined phenolic compounds derived from fruit juice analyses) for 5 cider cultivars and 5 dessert cultivars. A, Plot of cultivar means. $\mathrm{B}$, Plot of parameter loadings.

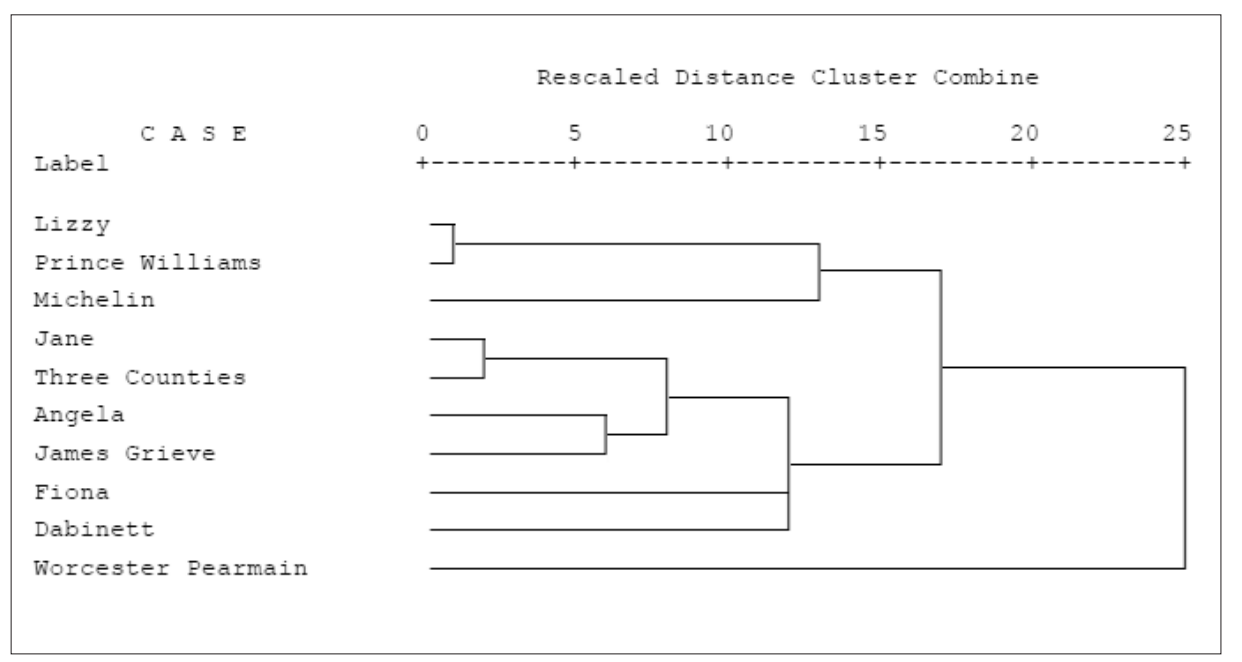

FIGURE 4. DNA based dendrogram showing parentage of the six new English cider cultivars. 
trast between cultivars (Figure 3A). Most cider cultivars are grouped to the right side of the scoreplot, indicating their higher SSC content and larger lesion diameter (Figure 3B). 'Angela' stands out mainly because of its high firmness at harvest.

\section{Parentage analysis}

The obtained DNA profiles were compared and parentage could be determined as follows: 'Angela', 'Fiona', 'Jane' and 'Three Counties' have been derived from a cross between 'Dabinett' and 'James Grieve' while 'Lizzy' and 'Prince William' instead originate from a cross between 'Michelin' and 'James Grieve'. A dendrogram (Figure 4) demonstrates a close similarity between 'Lizzy' and 'Prince William' which cluster with 'Michelin'. The other, larger cluster, contains the two parents 'James Grieve' and 'Dabinett' together with their offspring. One of the potential parents (Copas, 2010), 'Worcester Pearmain', splits off from the remainder as expected since it was not involved in the descent of the presently investigated Long Ashton cultivars.

\section{Discussion}

\section{Cider apple quality}

The present study aimed at determining the feasibility of growing English and French cider cultivars in Sweden. In order to study a relatively large number of cultivars, we used fruit harvested at two different locations which may have increased statistical estimates for inter-cultivar differences and decreased estimates for associations between variables (due to more 'noise'). However, the major aim was to compare fruit quality when these cultivars were grown in Sweden and in other countries, respectively.

Harvesting was undertaken from September 23 to October 12 , which is similar to what has been reported for early to mid-season cultivars when grown in their home countries but somewhat earlier than reported for late-ripening cultivars like 'Brown Snout', 'Dabinett', 'Judeline' and 'Vilberie'. In order to avoid fruit drop and mechanical damage, the fruit in our study was, however, picked at an earlier maturation stage compared to what is usually recommended in English and French cider orchards.

An ideal English cider apple should produce a juice with approximately 15\% sugar (Lea, http://www.cider.org.uk). In our study, sugar contents were generally higher in both juice and pulp of cider cultivars compared to dessert cultivars, but $15 \%$ sugar in the juice was achieved by only 5 cider cultivars. SSC was, however, measured in juice from fresh fruit harvested when half of the apple cut area showed signs of starch break-down. In England, harvest is usually delayed until most of the starch has broken down, and the fruit is subsequently stored for 1-2 months to raise the sugar content even further. With these procedures, at least another 8 cider cultivars (presently 13.5-14.4\% in our study) would most likely have reached desirable sweetness.

The ideal acid content in a cider apple can be defined as $0.4 \%$, and an overall acidity of $0.3-0.7 \%$ is aimed for in the juice (Lea, http://www.cider.org.uk). In our study, acidity varied considerably, with a similar range in cider apples and dessert apples. Seven of the cider cultivars had a higher acidity (0.50-1.71) while 12 were below the ideal value. The commonly acknowledged threshold $(0.45 \%)$ for discrimination between sharp and non-sharp cider cultivars was not violated by any of the 19 samples in our study.

Most cultivars in the present study still fell into the same categories as previously reported (Williams, 1975; Merwin et al., 2008; Copas, 2010; Moulton et al., 2010). However, as in the study by Alexander et al. (2016), the threshold for bitter $\left(0.20 \%\right.$ tannins or $\left.2.0 \mathrm{mg} \mathrm{GAE} \mathrm{g}^{-1}\right)$ was not reached by 'Kingston Black' (1.65, commonly classified as sharp/bittersharp) and 'Yarlington Mill' (1.45, commonly classified as bittersweet). The Long Ashton cultivar 'Lizzy' (1.69, commonly classified as bittersweet) was also below. Interestingly, one of the dessert cultivars, 'Luke', would have been classified as a bitter if it had been a cider apple, while another dessert cultivar, 'Ingrid Marie', had more phenols in the pulp than almost all of the cider cultivars. The two samples of 'Harry Masters Jersey' had 4.64 and $2.68 \mathrm{mg} \mathrm{GAE} \mathrm{g}^{-1}$, respectively. Environmental impact has a strong effect on tannin contents in dessert cultivars, as reported in orchard management trials (Tahir and Nybom, 2013), and most likely also in cider apples.

Of the 7 phenolic compounds analysed in the present study, chlorogenic acid had the highest concentration. High amounts of this compound were found also by Tsao et al. (2003) in the flesh of dessert cultivars, and by Sanoner et al. (1999) in the flesh of French cider cultivars, but both reported even higher amounts of epicatechin and procyanidin B2. The predominant dihydrochalcones were phloridzin, in accordance with Tsao et al. (2003), and a phloretin pentosylhexoside which may be identical to the phloretin xyloglucoside reported by Sanoner et al. (1999) and Tsao et al. (2003). Except for catechin (somewhat higher levels in dessert fruit), phenolic compounds were more abundant in cider cultivars as previously reported (Sanoner et al., 1999; Kahle et al., 2005). Polyphenols such as hydroxycinnamic acids (e.g., chlorogenic acid) are precursors of volatile compounds that contribute to cider aroma (Wojdylo et al., 2008) but more research is needed on the importance of the individual phenolic substances for producing cider with the desired bitter taste.

The analysed cider cultivars differed considerably in their content of phenolic compounds, with the French 'Vilberie' being among the top four for all except phloridzin. Above-average values were noted also for the traditional English cultivars 'Dabinett' and 'Harry Masters Jersey' (especially the fruit harvested at MarkCider), all three of which are considered to have vintage quality and therefore used for manufacturing single-variety cider. The highest amount of the very interesting compound phloridzin was found in 'Frequin Rouge' and 'Dabinett'. When ingested by humans, phloridzin has proven to decrease intestinal glucose absorption and may thus protect against prediabetes and diabetes mellitus type 2 (Schulze et al., 2014).

\section{Blue mould susceptibility}

Apple cultivars vary considerably in their susceptibility to blue mould, but to the best of our knowledge, tolerance against this disease has not been investigated before in cider cultivars. The present study was conducted on 5 Swedish-grown cider cultivars, with 5 dessert cultivars included for comparison in 2016 and 3 in 2017. One of the least damaged dessert cultivars in the present study, 'Olga', was among the most tolerant also in a previous two-year study of Swedish-grown apple cultivars (Tahir et al., 2015). In the same study, 'Bersis' and 'Ingrid Marie' were tolerant to medium susceptible, 'Elise' was medium susceptible while 'Luke' was medium to highly susceptible. The 5 cider cultivars were, however, more susceptible than any of the 5 dessert cultivars in the present study in 2016, and 4 of them were more susceptible than any of the dessert apples in 2017. This 
result is opposite to the initial hypothesis, and suggests that harvesting of cider cultivars should be conducted with great care to avoid mechanical damage acting as entry point for blue mould and causing fruit loss during storage as well as patulin contamination.

\section{Factors involved in blue mould tolerance}

Pronounced resistance against blue mould has never been reported in Malus $\times$ domestica cultivars. Two QTLS were, however, recently identified in a seedling progeny from a cross between a blue mould-resistant $M$. sieversii genotype and the moderately tolerant 'Royal Gala' (Norelli et al., 2017). The most influential of these QTLs, mapped to linkage group 3, is apparently inherited from the resistant $M$. sieversii parent. The very strong resistance found in this genotype is hypothesized to stem from the induction of a resistance response after initial pathogen detection. The second QTL, mapped to linkage group 10, is presumably inherited from 'Royal Gala'. Genes and QTLs for firmness and ripening have previously been found in the same region, and may be involved in this lower-level resistance. Thus, variation in blue mould lesion diameter is apparently associated with differences in fruit texture; above-average resistant dessert cultivars have comparatively high levels of fruit firmness at harvest and low levels of fruit softening (Ahmadi-Afzadi et al., 2013; Naeem-Abadi et al., 2014; Tahir et al., 2015). Number of analysed cultivars was, however, considerably smaller in the present study, and correlation coefficients were not significant in spite of indicating corresponding relationships. Moreover, there was no overall difference between cider and dessert cultivars in terms of fruit firmness or softening.

The commonly observed decline in resistance as the fruit matures (Norelli et al., 2017) may be connected also to changes in SSC and acidity. Previous analyses of fruit from mid- to late-ripening dessert cultivars (similar to the ones used in the present study) show about 10\% increase in SSC and 50\% decrease in acidity from the first harvest to the last harvest four weeks later (Tahir and Nybom, 2013). In the present study, great care was taken to use fruits of the same ripening stage. Cultivar-specific levels of SSC and acidity may, however, affect resistance. SSC (overall higher in the cider cultivars) was positively correlated with lesion diameter in this study, indicating that sweeter apples are more susceptible to blue mould. A negative association, although not significant, was noticed between titratable acidity (TTA) and lesion diameter. Similar associations with SSC and TTA have been reported by Janisiewicz et al. (2008) for a M. sieversii germplasm collection, and by Naeem-Abadi et al. (2014) for Iranian cultivars. By contrast, there was no relationship with SSC values in a study of Norwegian- and Swedish-grown apple cultivars (Tahir et al., 2015), or with TTA in another study (Chavez et al., 2014).

High levels of total polyphenols (TPH) in the fruit may contribute to resistance against blue mould (Blazek et al., 2007; Janisiewicz et al., 2008, Ahmadi-Afzadi et al., 2015; Naeem-Abadi and Keshavarzi, 2016). In addition, Ahmadi-Afzadi et al. (2015) found a negative correlation between content of PB2 in fruit flesh and lesion diameter. This correlation was especially strong when samples from inoculated fruits were analysed, indicating that disease development had triggered a phenolics-based defense reaction as suggested also by Naeem-Abadi and Keshavarzi (2016). Similarly, concentrations of several compounds, incl. PB2, CHL, EPI and PHL, were higher in three resistant accessions of the related species M. sieversii, M. sylvestris and M. × soulardii compared with two susceptible accessions, one of which was 'Golden Delicious' (Sun et al., 2017). These results suggest that resistance against blue mould is constitutive and based on high contents of various polyphenols.

However, results of the present study point in the opposite direction; positive correlations were found between PB2, EPI and TAG on the one hand, and lesion diameter on the other hand. In addition, lesion diameter increased, although not significantly, with higher contents of TPH, CHL, CAT, PHL and PHP. These data suggest that the high polyphenols content found in the fruit of 5 cider cultivars did not make them less vulnerable to blue mould attacks compared to the simultaneously inoculated fruit of dessert cultivars with considerably lower concentrations of polyphenols. Analyses were made on juice in our study, and on fruit flesh in most of the other studies (Ahmadi-Afzadi et al., 2015; Sun et al., 2017) but there is no reason to believe that this would make a large impact on the chemical evaluations; the major difference in phenolic contents was between cider apples and dessert apples just as expected.

The five cider cultivars used in the inoculation experiment are chemically rather similar (Figure 2). In addition, our DNA analyses show that all of them have the medium blue mould-susceptible 'James Grieve' (Ahmadi-Afzadi et al., 2013) as one parent, but unfortunately nothing is known about the status of the other parents, i.e., 'Dabinett' and 'Michelin', in this respect.

\section{Conclusions}

Fruit ripening of the investigated cider cultivars was somewhat later in Sweden than in the home countries, but adequate fruit quality could be achieved also in relatively late-ripening cultivars. In spite of being picked at a comparatively early ripening stage, almost all cultivars conformed to the common classification categories although tannin content was somewhat low in a few cases. Susceptibility to blue mould was unexpectedly high, and the high levels of phenolics in the fruit do not seem to offer sufficient protection. Perhaps, the relatively high sugar content (where cider cultivars and dessert cultivars are particularly different) and relatively low acidity, has had a major impact on susceptibility. Another possibility is that these particular cider cultivars have inherited a genetically determined susceptibility, unrelated to chemical contents and texture, from their common parent 'James Grieve'. Analysis of chemical contents and blue mould symptoms in a wider array of cider apples could provide valuable information on factors involved in the resistance.

\section{Acknowledgments}

We thank Claes Mark at MarkCider for contributing fruit to this study, Matt Ordidge at National Fruit Collection Brogdale, for contributing leaf samples for DNA analysis, and the field personnel at Balsgård for maintenance of the cider apple growth trial. Financial support was received from Partnerskap Alnarp, SLU, and from Nordic Ministries of Food and Agriculture through the Nordic collaboration on Public-Private Partnership for pre-breeding administered by NordGen.

\section{References}

Ahmadi-Afzadi, M., Tahir, I., and Nybom, H. (2013). Impact of harvesting time and fruit firmness on the tolerance to fungal storage diseases in an apple germplasm collection. Postharv. Biol. Technol. 82, 51-58. https://doi.org/10.1016/j.postharvbio.2013.03.001. 
Ahmadi-Afzadi, M., Nybom, H., Ekholm, A., Tahir, I., and Rumpunen, K. (2015). Biochemical contents of apple peel and flesh affect level of partial resistance to blue mold. Postharv. Biol. Technol. 110,173182. https://doi.org/10.1016/j.postharvbio.2015.08.008.

Alexander, T.R., King, J., Zimmerman, A., and Miles, C.A. (2016). Regional variation in juice quality characteristics of four cider apple (Malus $\times$ domestica Borkh.) cultivars in Northwest and Central Washington. HortScience 51, 1489-1502. https://doi. org/10.21273/HORTSCI11209-16.

Blazek, J., Opatova, H., Golias, J., and Homutova, I. (2007). Ideotype of apple with resistance to storage diseases. HortScience 34,107-113.

Chavez, R., Peniche, R., Medrano, S., Munoz, L., Ortiz, M., Espasa, N., and Sanchis, R. (2014). Effect of maturity stage, ripening time, harvest year and fruit characteristics on the susceptibility to Penicillium expansum Link. of apple genotypes from Queretaro Mexico. Sci. Hortic. 180, 86-93. https://doi.org/10.1016/j.scienta.2014.10.014.

Copas, L. (2010). 21 $1^{\text {st }}$ Century Cider Apples; Early Harvesting Cultivars from Long Ashton Research Station, Reading, UK.

Garkava-Gustavsson, L., Kolodinska Brantestam, A., Sehic, J., and Nybom, H. (2008). Molecular characterisation of indigenous Swedish apple cultivars based on SSR and S-allele analysis. Hereditas 145, 99-112. https://doi.org/10.1111/j.0018-0661.2008.02042.x.

Janisiewicz, W.J., Saftner, R.A., Conway, W.S., and Forsline, P.L. (2008). Preliminary evaluation of apple germplasm from Kazakhstan for resistance to postharvest blue mold in fruit by Penicillium expansum. HortScience 43, 420-426. https://doi.org/10.21273/ HORTSCI.43.2.420.

Kahle, K., Kraus, M., and Richling, E. (2005). Polyphenol profiles of apple juices. Molec. Nutr. Food Res. 49, 797-806. https://doi. org/10.1002/mnfr.200500064.

Lea, A.G.H. (1995). Cidermaking. In Fermented Beverage Production, A.G.H. Lea, and J.R. Piggott, eds. (Glasgow: Blackie), p. 66-96. https:// doi.org/10.1007/978-1-4757-5214-4_4.

Lea, A.G.H. (2017). http://www.cider.org.uk (accessed April 15, 2017)

Merwin, I.A., Valois, S., and Padilla-Zakour, O.I. (2007). Cider apples and cider-making techniques in Europe and North America. Hortic. Rev. 34, 365-415. https://doi.org/10.1002/9780470380147.ch6.

Moulton, G.A., Miles, C., King, J., and Zimmerman, A. (2010). Hard Cider Production and Orchard Management in the Pacific Northwest (WSU Extension Publishing, Washington State University, USA).

Naeem-Abadi, T., and Keshavarzi, M. (2016). Involvement of protective enzymes and phenols in decay (Penicillium expansum) resistance in apple. J. Agric. Sci. Technol. 5, 349-357. https://doi. org/10.18869/modares.jcp.5.3.349.

Naeem-Abadi, T., Keshavarzi, M., Alaee, H., Hajnajari, H., and Hoseinava, S. (2014). Blue mold (Penicillium expansum) decay resistance in apple cultivars and its association with fruit physicochemical traits. J. Agric. Sci. Technol. 16, 635-644.

Norelli, J.L., Wisniewski, M., Fazio, G., Burchard, E., Gutierrez, B. Levin, E., and Droby, S. (2017). Genotyping-by-sequencing markers facilitate the identification of quantitative trait loci controlling resistance to Penicilliun expansum in Malus sieversii. PLoS ONE 12(3):e0172949. doi:10.1371/journal.pone0172949.

Pianzzola, M.J., Moscatelli, M., and Vero, S. (2004). Characterization of Penicillium isolates associated with blue mold on apple in Uruguay. Plant Dis. 88, 23-28. https://doi.org/10.1094/PDIS.2004.88.1.23.

Pitt, J.I., and Hocking, A.D. (2009). Fungi and Food Spoilage (US: Springer). https://doi.org/10.1007/978-0-387-92207-2.
Sanoner, P., Guyot, S., Marnet, N., Molle, D., and Drilleau, J.P. (1999). Polyphenol profiles of French cider apple varieties (Malus domestica sp.). J. Agric. Food Chem. 47, 4847-4853. https://doi.org/10.1021/ jf990563y.

Schulze, C., Bangert, A., Kottra, G., Geillinger, K.E., Schwanck, B., Vollert, H., Blaschek, W., and Daniel, H. (2014). Inhibition of the intestinal sodium-coupled glucose transporter 1 (SGLT1) by extracts and polyphenols from apple reduces postprandial blood glucose levels in mice and humans. Mol. Nutr. Food Res. 58, 1795-1808. https://doi.org/10.1002/mnfr.201400016.

Singleton, V.L., Orthofer, R., and Lamuela-Raventos, R.M. (1999). Analysis of total phenols and other oxidation substrates and antioxidants by means of Folin-Ciocalteu reagent. Meth. Enzymol. 299, 152-178. https://doi.org/10.1016/S0076-6879(99)99017-1.

Smith, R.B., Lougheed, E.C., Franklin, E.W., and McMillan, I. (1979). The starch iodine test for determining stage of maturation in apples. Can. J. Plant Sci. 59, 725-735. https://doi.org/10.4141/cjps79-113.

Sun, J., Janisiewicz, W.J., Nichols, B., Jurick II, W.M., and Chen, P. (2017) Composition of phenolic compounds in wild apple with multiple resistance mechanisms against postharvest blue mold decay. Postharv. Biol. Technol. 127, 68-75. https://doi.org/10.1016/j. postharvbio.2017.01.006.

Tahir, I., and Nybom, H. (2013). Tailoring organic apples by cultivar selection, production system, and postharvest treatment to improve quality and storage life. HortScience 48, 92-101. https://doi. org/10.21273/HORTSCI.48.1.92

Tahir, I.I., Nybom, H., Ahmadi-Afzadi, M., Røen, K., Sehic, J., and Røen, D. (2015). Susceptibility to blue mold caused by Penicillium expansum in apple cultivars adapted to a cool climate. Eur. J. Hortic. Sci. 80, 117-127. https://doi.org/10.17660/eJHS.2015/80.3.4.

Tsao, R., Yang, J., Young, C., and Zhu, H. (2003). Polyphenolic profiles in eight apple cultivars using high-performance liquid chromatography (HPLC). J. Agric. Food Chem. 51, 6347-6353. https://doi.org/10.1021/jf0346298.

Williams, R.R. (1975). An Introduction to Modern Cider Apple Production (Bristol, England: Long Ashton Research Station).

Wojdylo, A., Oszmianki, J., and Laskowski, P. (2008). Polyphenolic compounds and antioxidant activity of new and old apple varieties. J. Agric. Food Chem. 56, 6520-6530. https://doi.org/10.1021/ jf800510j.

Received: Jun. 2, 2017

Accepted: Apr. 18, 2018

Addresses of authors:

Tim Spoor ${ }^{1}$, Kimmo Rumpunen ${ }^{1}$, Jasna Sehic ${ }^{1}$,

Anders Ekholm ${ }^{1}$, Ibrahim Tahir ${ }^{2}$ and Hilde Nybom ${ }^{1, *}$

${ }^{1}$ Department of Plant Breeding, Balsgård, Swedish

University of Agricultural Sciences, Fjälkestadsvägen 459,

SE-29194 Kristianstad, Sweden

2 Department of Plant Breeding, Swedish University of Agricultural Sciences, Box 101, SE-23053 Alnarp, Sweden

* Corresponding author; E-mail: hilde.nybom@slu.se

Tel.: +4644265802, +46703444369 